\title{
Fungi Causing Post-Harvest Spoilage Carica papaya Linn Fruits of Two Selected Markets in Kano State, Nigeria
}

\author{
${ }^{1}$ JAHUN, BM; ${ }^{2}$ ILU, KJ; ${ }^{1}$ YAHAYA, SM; ${ }^{2}$ AHMED, B; *2SALAMI, KD \\ ${ }^{I}$ Department of Biology Kano University of Science and Technology Wudil, Nigeria \\ ${ }^{* 2}$ Department of Forestry and Wildlife Management, Federal University Dutse, Nigeria \\ *Corresponding Author Email: foristsalam@yahoo.com; bmjahun146@gmail.com;Tel: +2348166248625
}

\begin{abstract}
This study was carried out for four month (September, 2015 to December, 2015) to find the fungal species associated with post-harvest spoilage of pawpaw fruits sales at Na'ibawa and Wudil Markets all in Kano State. A total of five strains of fungi were isolated and identified as Aspergillus niger, Aspergillus flavuus, Rhizophus stolonifer, Yeast, and Fusarium. Pathogenicity test of each fungal isolate showed that all fungi were capable of causing rotting of the fruit and most severe rotting was caused by Aspergillus niger and Yeast with $8(29.63 \%)$ Respectively at Na'ibawa market and $10(34.48 \%)$ and 9(31.03\%) at Wudil market followed by Rhizophus with 7(25.93\%) and $5(17.25 \%)$ while Aspergillus flavus and Fusarium produced the least rotting of the fruit. The difference in the fungal spoilage of Carica papaya between the two market areas Na'ibawa and Wudil markets was statistically significant $(\mathrm{p} \geq 0.05)$. From the result of this study, it is clearly indicated that the spoilage of pawpaw fruits in the two markets was due to fungal attack.
\end{abstract}

\section{DOI:https://dx.doi.org/10.4314/jasem.v25i5.6}

Copyright: Copyright $(92021$ Jahun et al. This is an open access article distributed under the Creative Commons Attribution License (CCL), which permits unrestricted use, distribution, and reproduction in any medium, provided the original work is properly cited.

Dates: Received: 20 March 2021; Revised: 27April 2021; Accepted: 07May 2021

Keywords: Fungi, Post-Harvest, Storage and Pawpaw

Fruits and vegetables are very important food components with high dietary and nutritional qualities (Barth et al., 2009). Their consumption has dramatically increased by more than $30 \%$ during the past few decades (Barth et al., 2009). Fresh fruit and vegetable consumption increased by $25.8 \%$ and $32.6 \%$, respectively, and far exceeded the increases observed for processed fruit and vegetable products. It is also estimated that about $20 \%$ of all fruits and vegetables produced is lost each year due to spoilage (Barth et al., 2009). Raven, et al., (2005) reported that 20 new human fungal pathogens are documented each year. It is estimated that about $20-25 \%$ of the harvested fruits are decayed by pathogens during post-harvest handling even in developed countries (Droby, 2006; Zhu, 2006).Fruits and vegetables are exposed to contamination by microbes through contact with soil, dust and water and by handling at harvest or during postharvest processing. This makes them to harbour a wide range of microorganisms including plant and human pathogens (Eni et al., 2010). Differences in microbial profiles of diverse fruits and vegetables result could be due to varying factors including resident microflora in the soil, application of nonresident microflora through animal manures, sewage or irrigation water, transportation and handling by individual retailers (Ofor et al., 2009). Deterioration of foods generally is attributed to two main causes which are natural degradation due to activities of enzymes and growth of microorganisms (bacteria, molds and yeasts). These microorganisms can result in useful products through their activities particularly during fermentation of foods such as wine and cheese. The negative effects of these microbial activities result in decay, rotting of food and food poisoning hence the basis of microbial food spoilage occurs when these microorganisms release their own enzymes into the foods and absorb the nutrients thereby changing the physical and chemical states of the foods thus lowering the nutritional value. Bacteria and fungi may also produce waste products which act as poisons or toxins, thus causing the renowned ill-effects (Bakri $e t$ al., 2010). Papaya fruit has high nutritive and medicinal value. The enzyme, papain, obtained from C. papaya is used as meat tenderizer, in manufacturing of chewing gum, in cosmetics (for shampoos and face lifting operation), and pharmaceutical industries. (Snowdon, 1990; Sherma, 1999). The edible portion of papaya is composed mostly of water $(86.8 \%)$ and carbohydrate principally sugars with little starch $(12.18 \%)$ which together make up $98.98 \%$ of the fruit (Awoite et al., 2013).The acid content of papaya is very low, this would account for its lack of tartness and its relative high $\mathrm{pH}$ value of 5.9.The fruit contain a major enzyme called papain which is proteolytic. Pawpaw has been utilized widely in brewing and 
pharmaceutical industries (William et al., 1980). Charley (1999) observed that fresh fruits carry out the physiological function of respiration, thereby absorbing and releasing gases and other materials from and to environment. This condition makes them susceptible to microbial infection under condition of high ambient temperature and relative humidity which lead to their deterioration during post-harvest period. Physiological stability of fruit varies, thus the main damage to the quality of the fruit does not occur generally until the microorganisms have gained access to the living tissues through the skin. Fruits come in contact with the disease causing organisms through different sources such as field infections or during harvesting if it comes in contact with the soil which is an important factor that aids spoilage of stored fruits. Therefore, the aim of this study is to isolate and identify the fungi associated with post-harvest spoilage of pawpaw fruits and to determine the pathogenicity effect of the different isolates on healthy pawpaw fruits to ascertain that the fungi isolated were capable of causing spoilage and produce the disease symptoms.

\section{MATERIALS AND METHOD}

Study areas: Na'ibawa market-Is located at the entrance of Kano from Kaduna in Kumbotso local government area of Kano state. Na'ibawa was chosen because it is a popular fruit market in Kano state with pawpaw abundance. Dealers store their fruits in sacks and baskets which may be washed with either fresh water or detergent hardly used chemical ionizers.

Wudi market-is located at Wudil Local Government area of Kano state. Wudil market is one of the largest cattle market in northern Nigeria. The popular market is also a center for the purchase fruits and vegetables. This study area is well known with no storage facilities of fruits and vegetables.

Experimental procedure: The methodology used in this study followed the one used by Yahayaet al., (2006). The investigation last for the period of four months from September, 2015 to December, 2015.

Sample collection: Four samples of pawpaw were collected twice in a week Mondays and Thursdays directly two from each market (Na'ibawa and Wudil market) and transported to Biology Laboratory Kano University of Science and Technology, Wudil in a sterile polythene bags.

Sample handling: Pawpaw fruits collected from Na'ibawa and Wudil markets were subjected to surface sterilization by washing with some distilled water and detergent it was later subjected to three changes of running tap water and allowed to dry. $2 \mathrm{~mm}$ portion was cut with a sterile scalpel the cut piece was placed on freshly prepared PDA plate and incubated at $27.5^{\circ} \mathrm{c}$ for three (3) days.

Isolation and sub-culture: In each week, growth of fungal colonies was monitored and the number of colonies that appeared was recorded. Pure isolates were obtained by selecting discrete colonies and having them sub-cultured on to Petri-dishes containing freshly prepared PDA.

Pathogenicity test: This was carried out as described by Baiyewu et al. (2007) and Chukwuka et al., (2010). Each of the fungal isolates was tested on healthy fruits for its ability to induce spoilage. Healthy fruits (Pawpaw) were washed with tap water and rinsed with distilled water after which they were surface sterilized with $75 \%$ ethanol. A sterile $2 \mathrm{~mm}$ cork borer was used to make holes in the fruit. A colony of fungi isolate (from each pure culture) was used to inoculate the fruit and the core of the fruit were replaced. Control Pawpaw, wounded with the sterilized cork borer but not inoculated. The inoculated fruits and the control were placed in clean polyethylene bag moistened with wet balls of absorbent cotton wool to create a humid environment and incubated at $30 \pm 1^{\circ} \mathrm{c}$ for 5 days. After $72 \mathrm{hrs}$, the inoculated fruits were observed for symptom development.

Photography: Photographs of fungal mycelia were taken from mounted slide using camera Lucida at Biology Laboratory Kano University of science and technology, Wudil.

Data Analysis: The data were analyzed statistically using one way analysis of variance (ANOVA) and differences among the means was determined for significance at $\mathrm{p} \leq 0.05$. This was achieved using a computer programme (SPSS, 16.0).

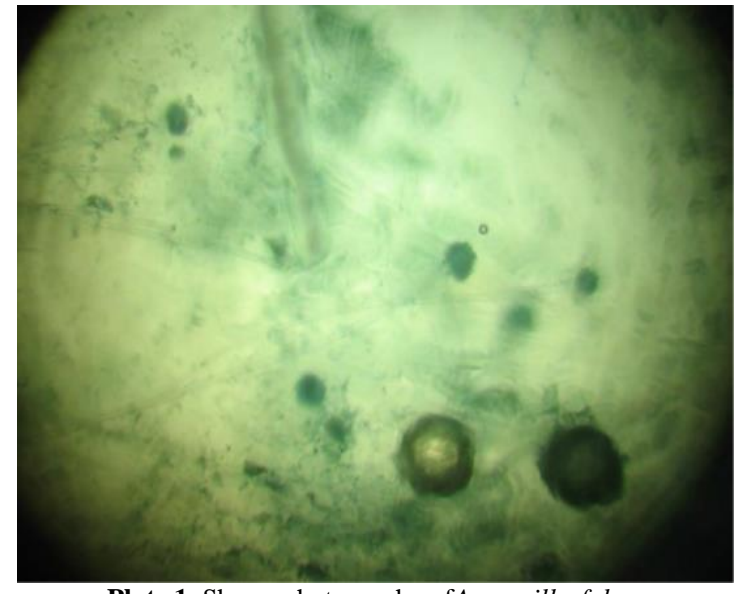

Plate 1. Shows photography of Aspergillusfalvus 


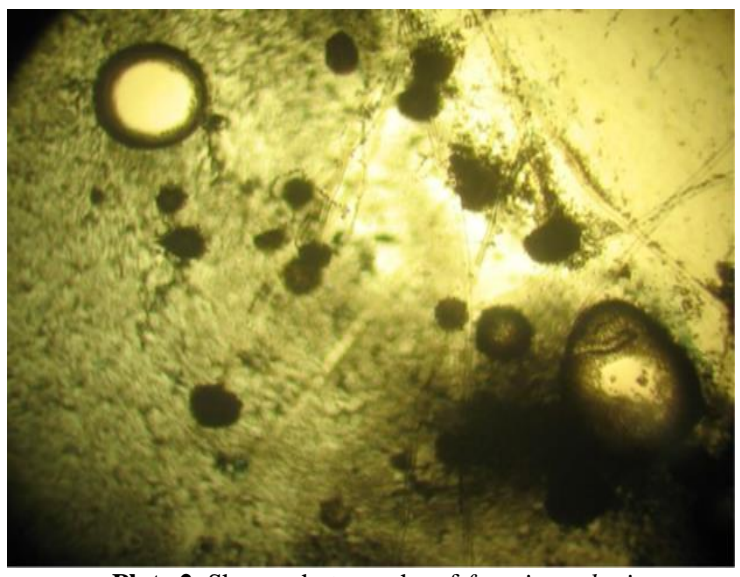

Plate 2. Shows photography of fusariumsolani

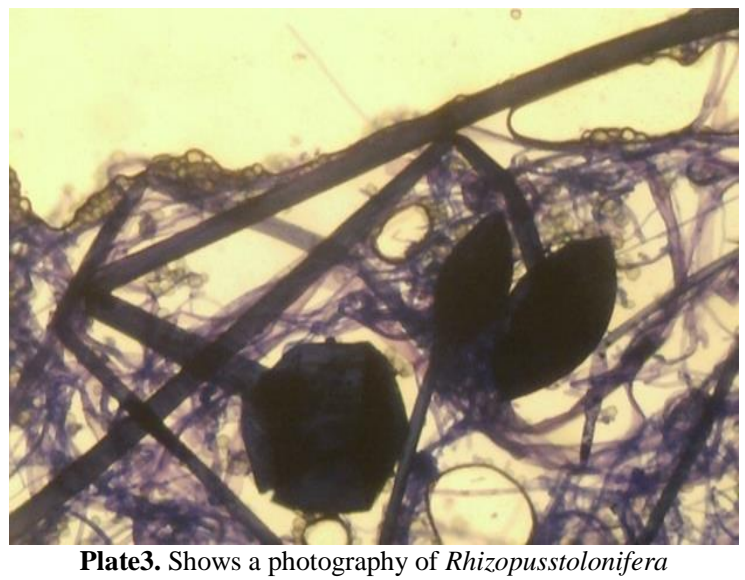

\section{RESULTS AND DISCUSSION}

A total of fifty six fungal species were counted during the investigation from both Na'ibawa and Wudil markets. A. niger and Yeast have the highest frequency of occurrence with $8(29.63 \%)$ respectively, Rhizopuss tolonifer and A. flavus are also moderately frequent with frequency of $7(25.93 \%)$ and $3(11.11 \%)$ while fusarium solani is the least occurring with $1(3.70 \%)$ at Na'ibawa market while the result from Wudil market showed that the same isolates from that of Na'ibawa market were also found to be the most occurring i.e. A. niger and Yeast with 10(34.40\%) and 9(31.035) respectively, followed by Rhizopuss tolonifer and A. flavus with 5(17.25\%) and 4(13.79\%) and fusarium solani was the least occurring with $1(3.45 \%)$ as shown in (table 1 and 2). This study revealed the microorganisms associated with spoilage of pawpaw fruits. The presence and isolation of these micro-organisms depict that they are the causal agent responsible for the deterioration of such an economical fruit. In all the isolates produced from the 12 samples collected from Naibawa and Wudil market, five micro-organisms namely: Aspergillus niger, Aspergillus flavus, Rhizopus, Yeast and Fusarium, belonging to five fungal genera were isolated and identified.Among the five fungal species isolated Aspergillus niger and Yeast with (32.14\%) and (30.36\%) respectively, were found to be the most frequently isolated fungi from the fruit, Rhizopus stolonifer and Aspergillus flavus with $(21.43 \%)$ and $(12.5 \%)$ respectively, were moderately frequent while fusarium solani with (3.57\%) is the least occurring fungal isolate from both markets. These pathogens have been reportedly isolated from Pawpaw fruits in Nigeria (Baiyewu et al., 2007; Chukwuka et al., 2010). All the five organisms isolated were confirmed to be pathogenic on the fruits but in varying degrees. It showed that of all the isolated fungi, Aspergilus niger and yeast was highly pathogenic leading to rapid disintegration of treated fruits in 3-5 days while R. stolonifer and Aspergilus flavus were moderately pathogenic, and fusarium solani was the least pathogenic and caused the least amount of rot on fruits. When these isolates were aseptically inoculated into healthy susceptible fruits, the characteristic symptoms originally observed were also noticed again. All the five organisms were successfully taking part in the decay and are thus confirmed as the causal organism of fruit decay (Baiyewu et al., 2007; Chukwuka et al., 2010).The fungi isolated in this study have been reported to produce secondary metabolites in plants tissues. These secondary metabolites are potentially harmful to humans and animals (Eaton and Groopman, 1994; Baiyewu et al., 2007). A good example is Aflatoxin which has been associated in cancer of the liver (heptatoma), aflatoxicosis and also with acute hepatitis in humans, especially in the developing world (Krogh, 1992; Prasad, 1992; Eaton and Groopman, 1994; Muhammad et al., 2004; Baiyewu et al., 2007).

Table 1. Shows the frequency and percentage of occurrence of fungal isolates from Na'ibawa market

\begin{tabular}{llllll}
\hline Week & A. niger & A. flavus & Rhizopus & Yeast & Fusarium \\
\hline 1 & 1 & 0 & 2 & 1 & 0 \\
2 & 2 & 0 & 0 & 1 & 0 \\
3 & 2 & 1 & 0 & 2 & 0 \\
4 & 1 & 2 & 2 & 1 & 0 \\
5 & 1 & 0 & 2 & 2 & 0 \\
6 & 1 & 0 & 1 & 1 & 1 \\
Total & 8 & 3 & 7 & 8 & 1 \\
Mean & 1.33 & 0.5 & 1.16 & 1.33 & 0.71 \\
$\%$ & 29.63 & 11.11 & 2593 & 29.63 & 3.70 \\
\hline
\end{tabular}

Table 2: Shows the frequency and percentage of occurrence of fungal isolates from Wudil market 


\begin{tabular}{lllllll}
\hline Week & A. niger & A. flavus & Rhizopus & Yeast & fusarium & Total \\
\hline 1 & 2 & 0 & 0 & 2 & 0 & \\
2 & 2 & 0 & 2 & 2 & 0 & \\
3 & 2 & 1 & 1 & 1 & 0 & \\
4 & 1 & 1 & 2 & 2 & 1 & \\
5 & 1 & 1 & 0 & 1 & 0 & \\
6 & 2 & 1 & 0 & 1 & 0 & 29 \\
Total & 10 & 4 & 5 & 9 & 1 & 4.48 \\
Mean & 1.67 & 0.67 & 0.83 & 1.5 & 0.17 & 100 \\
$\%$ & 34.38 & 13.79 & 17.25 & 31.03 & 3.45 & \\
\hline
\end{tabular}

Table 3: shows the frequency and percentage distribution of fungal isolates from both Na'ibawa and Wudil markets respectively

\begin{tabular}{lllllll}
\hline Week & B. niger & B. flavus & Rhizopus & Yeast & fusarium & Total \\
\hline 1 & 3 & 0 & 2 & 3 & 0 & \\
2 & 4 & 0 & 2 & 3 & 0 & \\
3 & 4 & 2 & 1 & 3 & 0 & \\
4 & 2 & 3 & 4 & 3 & 1 & \\
5 & 2 & 1 & 2 & 3 & 0 & \\
6 & 3 & 1 & 1 & 2 & 1 & 56 \\
Total & 18 & 7 & 12 & 17 & 2 & 9.33 \\
Mean & 3 & 1.17 & 2 & 2.83 & 0.33 & 100 \\
$\%$ & 32.14 & 12.5 & 21.43 & 30.36 & 3.57 & \\
\hline
\end{tabular}

It was confirmed that more fungal colonies were identified at Wudil market than Na'ibawa which could be as a result of high commercial activities with high conjunction of people from all over the country in Wudil market being the leading cattle market in the country. The influx of people and animals from different part of Nigeria to Wudil market may lead to the introduction of foreign pathogenic microorganisms and other environmental pollutants in to the market area, such pollutants could favour the growth and reproduction of microbes compared to the lower number of fungal species isolated from $\mathrm{Na}$ 'ibawa market were the major commodities in the market area are fruits and vegetables.

Conclusion: Research conducted on the fungi causing post harvesting spoilage of pawpaw fruit. Aspergillus niger and yeast occurred with highest frequency. High rate of this fungi occurred as a result of high commercial activities with conjunction of people from all over the country in Wudil market being the leading cattle market in the country. Social amenities and infrastructural facilities were recommended that there is need to prevent the occurrence of such economic loss and possible health hazard measured have to be adapted in order to minimize fruits contamination by fungi. The use of chemicals and fungicides eradicants to both the plants and the soil could help to check the wide spread of the spoilage fungi; the spray to the soil will help to prevent the soil fungi which constitute the major sources of contamination.

\section{REFERENCES}

Awoite, T M; Olorunfemi M F; Ajani A O; Oyelakin M O (2013). Studies on Fungi Associated With Post Harvest Spoilage of Pawpaw Carica PAPAYA Fruit: J. Pharm. Biol. Sci. 4: 01-04
Baiyewu, RA; Amusa, NA; Ayoola, OA; Babalola, OO (2007). Survey of the Post-Harvest Diseases and Aflatoxin Comtamination of Marketed Pawpaw Fruit (Carica papaya L.). Afr. J. Agric. Res. 2(4):178-181

Bakri, Y; Masson, M; Thonart, P. (2010). Isolation and identification of two new fungal strains for xylanase production. Appl. Biochem. Biotechnol. 162:1626-1634.

Barth, M; Hankinson, T R; Zhuang, H; Breidt, F. (2009). Microbiological Spoilage of Fruits and Vegetables. Compendium of the Microbiological Spoilage of Foods and Beverages, Food Microbiology and Food Safety. Springer Science Business Media, LLC: 135-183.

Charley, V L, (1999). The Prevention of microbiological spoilage in fresh fruit in: and Food Journal of Science Agriculture. 10: 399400 .

Chukwuka, KS, Okonko, IO, Adekunle A.A (2010). Microbial Ecology of Organisms Causing Pawpaw (Carica Papaya L.) Fruit Decay in Oyo State, Nigeria. Am-Eurasian J. Topical. Sci. 2 (1): 43-50

Dorathea, F, Ronald, J. and Ronald C B (1976): A colour atlas of pathogenic fungi. Wolfe medical publication Ltd. Pp: 12-53

Droby S. (2006): Improving quality and safety of fresh fruits and vegetables after harvest by the use of biocontrol agents and natural materials. Acta Horticulture. 709: pp: 45-51. 
Eni, A. O., Oluwawemitan, T. O. and Solomon O. U, (2010). Microbial quality of fruits and vegetables sold in Sango Ota, Ogun State, Nigeria. Afr. J. Food Sci. 4(5): 291-296.

FAO (2001) Manual on the application of the HACCP system in mycotoxins prevention and control. FAO Food and nutrition paper 73. FAO Rome, Italy.

Muhammad S, Shehu K, Amusa NA (2004). Survey of the market diseases and aflatoxin contamination of Tomato (Lycopersiconesculentum MILL) fruits in Sokoto North western Nigeria. Nutrit. Food Sci. 34:72-76.

Ofor, M. O, Okorie, V. C., Ibeawuchi, I. I., Ihejirika, G. O, Obilo, O. P, and Dialoke, S. A. (2009). Microbial Contaminants in Fresh Tomato Wash Water and Food Safety Considerations in SouthEastern Nigeria. Life Sci. J. 1:80-82.

Sherma, R L. (1999). Atlas of Post-Harvest Diseases of Tropical and Subtropical Fruits: In Diseases in Horticultural Crop Fruit. Indian Publishing Company, New Delhi (India) pp. 624-667.
Snowdon, A. L. (1990). Atlas of Post-Harvest Diseases and Disorder of Fruit and Vegetables

William CN, Chew YW, Rajartham JH (1980). Papaya In: Encyclopedia of Food Science and Technology. Academic press Ltd. London 2: 3408-3411

Yahaya S.M, and Fatima A. (2009): fungal deterioration of dried yam chips on sale in gwo selected markets in Kano state-Nigeria. Techno Sci. Afr. J. (4)1 10-12

Zhu, S J (2006). Non-chemical approaches to decay control in postharvest fruit. In: Noureddine, B., Norio, S. (Eds.), Advances in Postharvest Technologies for Horticultural Crops. Research Signpost, Trivandrum, India, pp. 297-313. 